\title{
Looking inside Panarea Island (Aeolian Archipelago, Italy) by gravity and magnetic data
}

\author{
Luca Cocchi $\left({ }^{1}\right)$, Fabio Caratori Tontini $\left({ }^{1}\right)$, Cosmo Carmisciano $\left({ }^{1}\right)$, Paolo Stefanelli $\left({ }^{1}\right)$, \\ Marco Anzidei $\left({ }^{2}\right)$, Alessandra Esposito $\left({ }^{2}\right)$, Ciro Del Negro $\left({ }^{3}\right)$, Filippo Greco $\left({ }^{3}\right)$ and Rosalba Napoli $\left({ }^{3}\right)$ \\ ${ }^{(}{ }^{1}$ Istituto Nazionale di Geofisica e Vulcanologia, Fezzano (SP), Italy \\ $\left(^{2}\right)$ Istituto Nazionale di Geofisica e Vulcanologia, Roma, Italy \\ $\left({ }^{3}\right)$ Istituto Nazionale di Geofisica e Vulcanologia, Sezione di Catania, Italy
}

\begin{abstract}
This paper shows and discusses the results of gravity and magnetic surveys of Panarea Island and its archipelago. The most recent volcanic manifestation occurred in November 2002 with a shallow submarine gas eruption between the islets of Dattilo, Panarelli, Lisca Bianca, Bottaro and Lisca Nera. Currently, the activity of Panarea is monitored through a multidisciplinary study under the umbrella of the Italian Department of Civil Protection with the goal of defining the hazard of this area. With this aim, in May 2006 the first gravity and magnetic surveys of Panarea Island and its archipelago were performed. The offshore magnetic data were obtained using a marine magnetometer, a Geometrics G880, from the Istituto Idrografico dell Marina (IIM). Onshore and offshore magnetic data were integrated into an unique dataset for complete magnetic coverage of the study area. By using two micro-gravimeters (LaCoste \& Romberg), gravity data were collected along tracks every $250 \mathrm{~m}$. The gravity dataset was processed using the standard method. A Bouguer reduction was applied to the free-air gravity dataset using a detailed digital elevation model of the island and the neighbouring sea after evaluation of the optimal Bouguer density to reduce the topographic effect. The result is a Bouguer anomaly map that shows lateral variations in density distribution and the relationships between the shallow volcanic/crustal features and tectonic lineaments. This evidence is also highlighted by the magnetic pattern, which suggests the importance of the youngest volcanic deposits with respect to the magnetic features of the island.
\end{abstract}

Key words magnetism-gravity - structural setting - Panarea Island - hydrothermal systems

\section{Introduction}

Panarea Island is part of the Aeolian Arc, which consists of seven islands and several

Mailing address: Dr. Luca Cocchi, Istituto Nazionale di Geofisica e Vulcanologia, U.P. Geofisica e Tecnologie Marine, Via Pezzino Basso 2, 19025 Fezzano (SP), Italy; e-mail: cocchi@ingv.it seamounts located in the Southern Tyrrhenian Sea. This volcanic island arc is currently characterized by active volcanism that recently affected Stromboli and Panarea Islands with lava eruptions and gas exhalation, respectively. The geodynamic evolution of the Aeolian arc is mainly connected to a NW-striking subduction system in which a portion of the Ionian plate is deep under the Calabrian Arc (Barberi et al., 1973; Beccaluva et al., 1985). The late phase of the Aeolian volcanism is related to the riftingtype process more than the subduction process (De Astis et al., 2003). This area is affected by shallow, intermediate and deep seismicity (Chiarabba et al., 2005) and active crustal de- 


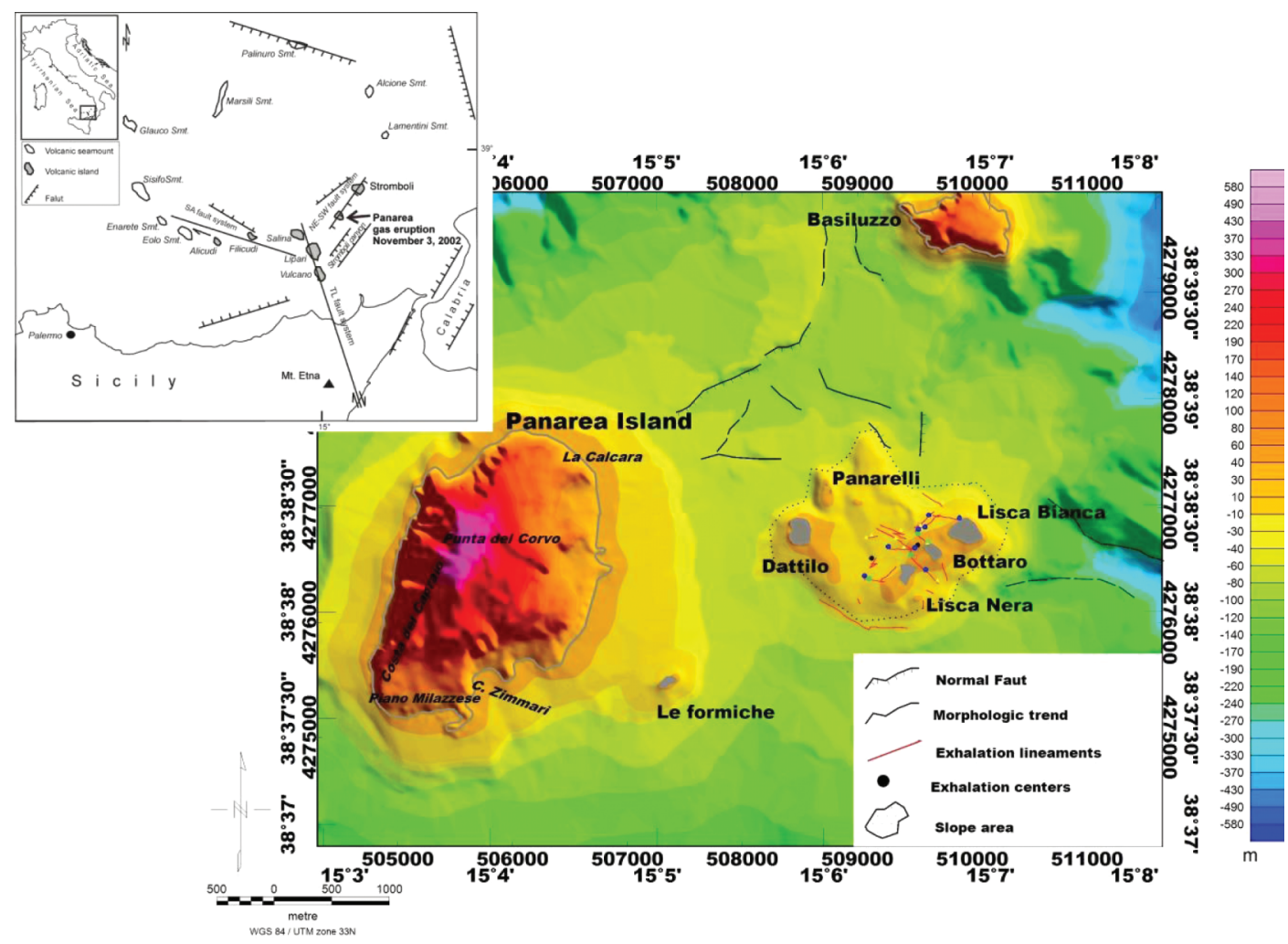

Fig. 1a,b. a) Aeolian Archipelago; b) Morphological and tectonic features of Panarea Island and its archipelago. The geographic positions of the exhalative centres are from Anzidei et al. (2005).

formation (Bonaccorso, 2002; Hollestein et al., 2003; D'Agostino and Selvaggi, 2004; Pondrelli et al., 2004; Serpelloni et al., 2005).

The arc is divided into two main parts by a NNW-SSE-striking fault called the «TindariLetoianni» fault system (Barberi et al., 1994; Mazzuoli et al., 1995; De Astis et al., 2003: Billi et al., 2006), where Salina, Lipari and Vulcano Islands are located (fig. 1a). The western sector of the Aeolian arc is formed by Glauco seamount, Alicudi and Filicudi Islands, where volcanism developed between 1.3 to $0.05 \mathrm{Ma}$ (Tranne et al., 2002a,b). In the eastern sector that extends from Panarea and Stromboli islands to Alcione and Palinuro seamounts, the volcanism is still active. At Stromboli the activity started about 200 ka (Gillot and Keller, 1993) with effusive and explosive eruptions during its formation. In particular, the activity of Panarea Island and its archipelago is characterized by offshore and onshore exhalative activities.

Panarea Island, located between Stromboli and Lipari Islands, is the smallest of the Aeolian archipelago. The emerging part of the Panarea volcano covers about $3.5 \mathrm{~km}^{2}$, with a NE-SW orientation (fig. 1b). It represents the sub-aerial portion of a submarine stratovolcano with a maximum depth of $\sim 2000 \mathrm{~m}$ and a length of $20 \mathrm{~km}$ (Gabbianelli et al., 1993; Gamberi et al., 1997; Favalli et al., 2005). The volcanism started about $150 \mathrm{ka}$ (Gabbianelli et al., 1990; Calanchi et al., 1999; Lucchi et al., 2003) with the deposition of lava domes and lava flows, mostly made of andesite to rhyolite, interbed- 
ded with pyroclastic deposits (Calanchi et al., 1999, 2002). Between $130 \pm 9$ and $54 \pm 8$ ka (Gabianelli et al., 1990), the volcanic activity formed the islets of Lisca Bianca, Lisca Nera, Dattilo, Panarelli and Basiluzzo. Pyroclastic deposits of external provenance cover the volcanic products of Panarea and its islets. This unit is dated between 70 and $8 \mathrm{ka}$ (Lucchi et al., 2007), clipping the older deposits and representing the last volcanic/eruptive event in the area. At present, volcanic activity produces submerged gas exhalation among the islets and several fumaroles located in the Calcara zone, north Panarea Island (see fig. 1b).

The last exhalative crisis of November 2002 occurred between Lisca Bianca, Bottaro and Dattilo islets in a shallow bathymetric area (30 $\mathrm{m}$ depth), affecting $\sim 2.3 \mathrm{~km}^{2}$ with about $10^{9}$ 1/day of erupted gas (Caracausi et al., 2005; Caliro et al., 2004; Anzidei et al., 2005).

Panarea is currently the object of multiparametric studies concerning geophysical and geochemical observations. We present the results of gravity and magnetic surveys.

The magnetic anomaly field is connected to lateral and depth variations in the magnetic contributions of magnetized rocks in the shallow crust. The magnetic anomaly field of Panarea Island and its archipelago were analyzed to describe the highly magnetized zones and to determine the relationship between the distribution of exhalative centres and magnetization trends. The offshore and onshore data were analyzed separately and integrated in a common dataset. The gravity analysis was limited to Panarea Island with a set of measurements covering the volcanic apparatus. A complete Bouguer reduction was computed following discretization of the bathymetry using a set of prismatic elements after a cross-plot analysis of the optimal Bouguer density.

The goal was to provide an interpretation of the Panarea volcanic system based on a new potential field dataset merged to the tectonic and structural features.

\section{Gravity survey and processing}

Microgravity survey of Panarea Island was performed in May 2006 covering the entire emerged portion of the island. The gravity data were sampled using a pair of LaCoste \& Romberg micro-gravimeters (Aliod model) equipped with a digital data acquisition system, GPS tracking and automatic tide corrections, with a nominal resolution of $1 \mu \mathrm{gal}$. The offset between the two instruments was analyzed at the beginning of the survey by recording the gravity data at the same set of stations. This procedure was designed to reduce the misfit values between the two instruments and to obtain a uniform gravity dataset. A reference station was fixed with known absolute gravity and placed at the minimum elevation to check the state of the apparatus and the quality of the measurements, and to estimate the instrumental drift. Since the gravity survey was performed following accessible paths, the measurement stations were not distributed according to a regular grid, but were scattered. Along the acquisition tracks, the gravity field was recorded using a spatial interval of $250 \mathrm{~m}$. The entire cone of Panarea Island was sampled through 92 stations (fig. 2). The geographic positions of the gravity stations were defined using the integrated position system of the gravimeter and a second portable GPS receiver. The gravity field was recorded with a couple of measurement sessions with a time-interval of $5 \mathrm{~min}$; for each station, station-ID, date, time, topography altitude (by GPS and altimeter) and GPS-position were collected. In order to check for instrumental drift, a set of stations was re-acquired daily. The full gravity dataset for Panarea was composed of two subsets connected to the two different instruments. This distinction was useful in the subsequent data processing, in particular for reducing instrumental drift. Each gravimeter is characterized by a different drift effect, which consists of a shift from the zero level during the recording time, and which is strictly connected to the mechanism and the electronics of the sensor.

For each gravimeter, the related dataset was divided by the time of acquisition. The LaCoste \& Romberg Aliod model sensor records tidal variation and automatically provides tide-corrected gravity data. The recorded gravity data were corrected using the daily drift value. This value was added to or subtracted from the data 


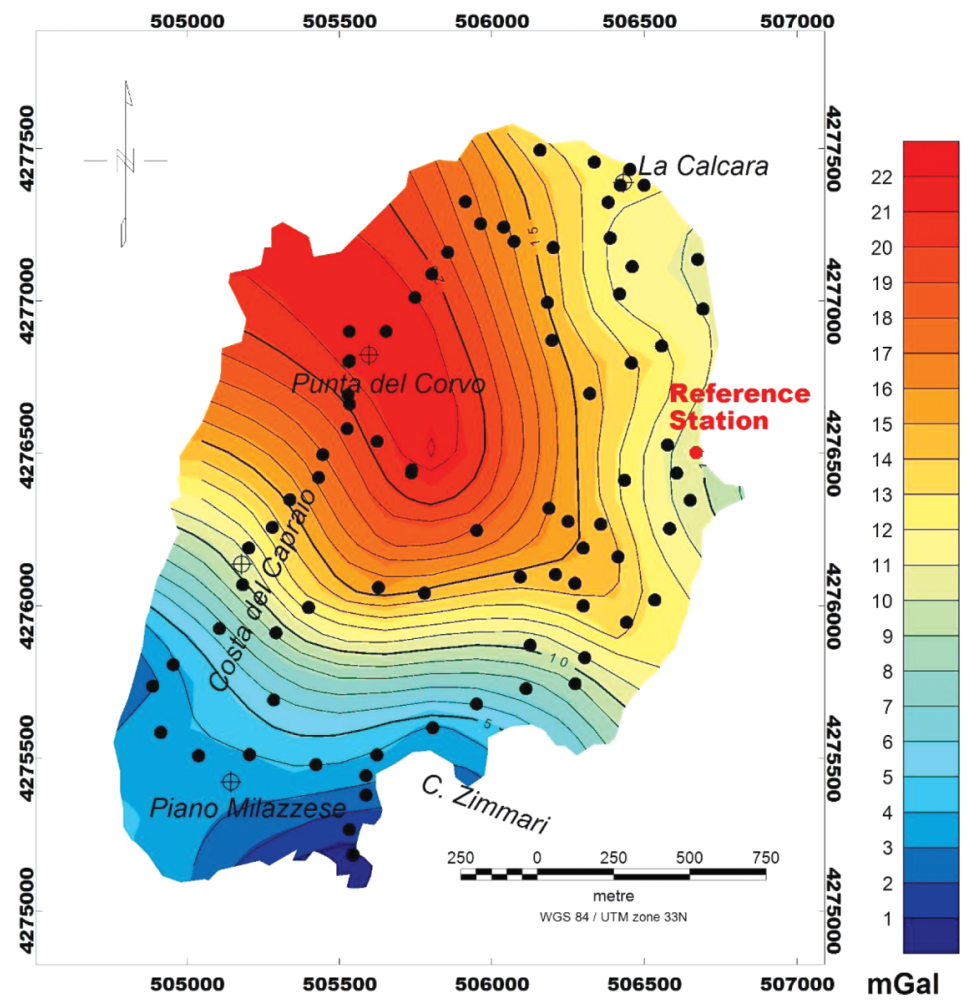

Fig. 2 Free air gravity anomaly map of Panarea Island (contour interval, $1 \mathrm{mGal}$ ) with geographic locations of measurement stations (black points); the red point is the reference station.

from each station based on the time of acquisition. This procedure provided a set of corrected gravity data, including the 92 measurement points and the reference station. The absolute gravity values were obtained by adding the known absolute gravity value of the reference station $(980231.98 \mathrm{mGal})$ to the whole set of collected data.

The tide-corrected gravity data were subsequently corrected using standard processing procedures. The first correction was the re-positioning of the recording station to a common reference surface as the geoid surface. Free air correction removes the difference in gravity due to the topographic level of the measurement station. Free air correction was applied to the tide-corrected gravity data for Panarea, producing the related free-air anomaly map (fig. 2).

The result of this first reduction was a distribution of the gravity anomaly strictly correlated to topographic evidence, as confirmed by a shape similarity between the anomaly and the topographic features of the Panarea cone (fig. 1b). In this case, the free-air anomaly, which had a positive range of values between 1 and 22 $\mathrm{mGal}$, provided less information on the crustal structure and the density distribution of Panarea. Thus far, local gravity sources were completely masked by the gravity component of the volcanic structure. A better resolution of the gravity field connected to the different geologic structures of the cone may be obtained by 
removing the topography component from the free-air data by performing a Bouguer correction.

A Bouguer correction removes the topography effect from the free air gravity dataset and is more effective in regions characterized by high topography/bathymetry gradients. The mass between the measurement points and sea level may be relevant in terms of gravity field, an effect ignored by the previously described free air correction. In the case of a slight topographic gradient, a Bouguer reduction may be limited to a simple correction in which all masses above sea level are considered as homogeneous and infinitely extended slab. Otherwise, for a region with rapid vertical development, such as a volcanic edifice, a Bouguer reduction must be calculated by considering the exact topography. A complete Bouguer correction is computed by applying a topography subdivision in different prisms and then calculating the gravity contribution of the prismatic ensemble. Bouguer anomaly field derives from the difference between the observed gravity and the sum of the gravity contributions of the prisms. In the case of Panarea Island, the free-air gravity field is affected by a strong topographic contribution which can be removed by taking into consideration a Bouguer reduction. Morphologically, Panarea is a stratovolcano characterized by a steep slope with a maximum height of 410 $\mathrm{m}$ in an area of $10 \mathrm{~km}^{2}$. Thus, Panarea represents a real case where a complete Bouguer reduction should be applied. However, the gravity field of a small island such as Panarea is contaminated by anomalous contributions from the surrounding off-shore and on-shore areas. This means that in the Bouguer reduction process, the gravity component of a larger area than the island itself should be considered. In this study, we applied a complete Bouguer reduction by considering two distinct areas with different

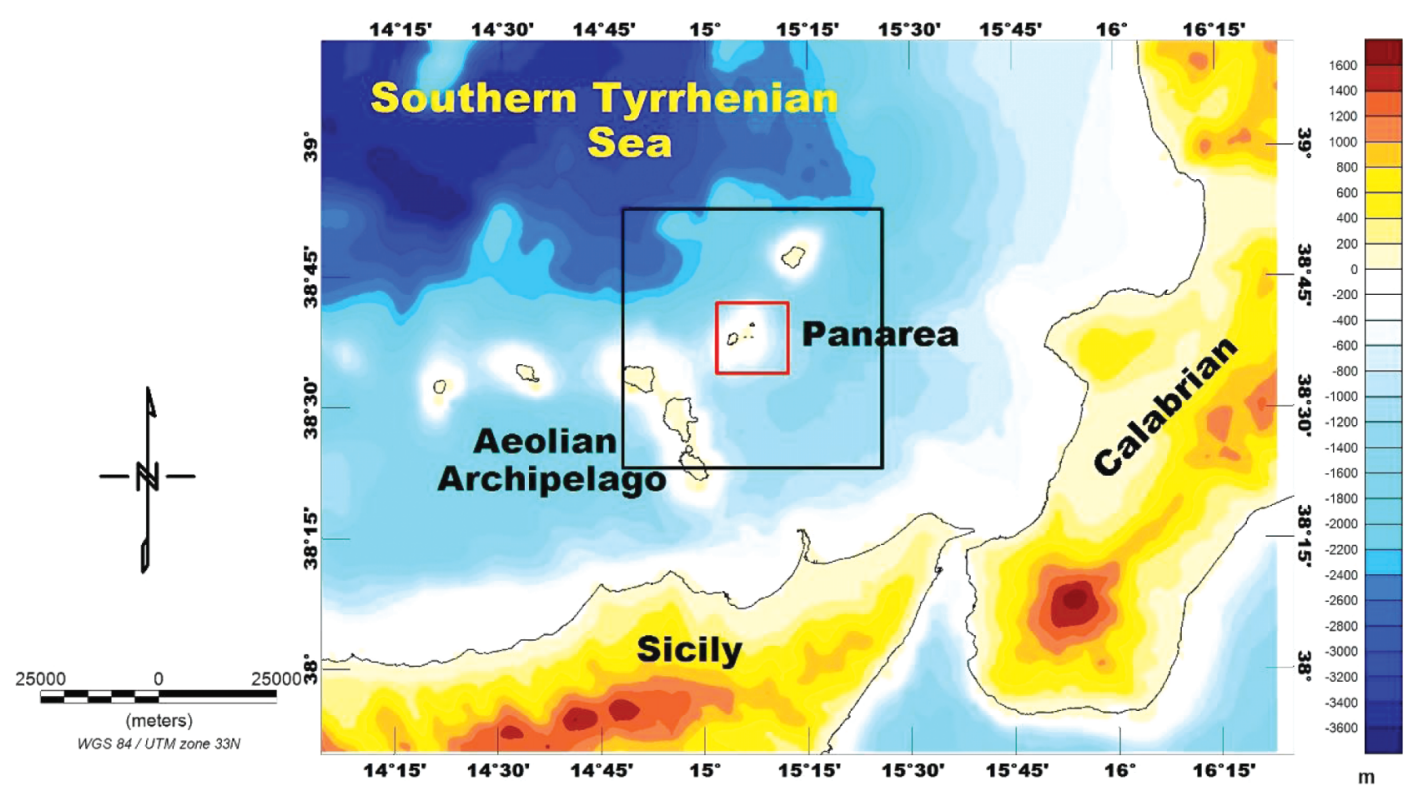

Fig. 3. Schematic figure showing the two areas used for Bouguer reduction. The red box is the perimeter of the detailed digital elevation model with a grid sampling factor of 200 meters. The black box delimits the large DEM at low resolution $(1 \mathrm{~km})$. 
geographical dimensions and data resolutions: a smaller square area centred on Panarea with a lateral extent of $\sim 22 \mathrm{~km}^{2}$ and a resolution of $100 \mathrm{~m}$ for the bathymetry data, and a larger square area of $\sim 70 \mathrm{~km}^{2}$ in which bathymetry and topography were sampled at $1 \mathrm{~km}$ of spatial intervals. The layouts of these two working areas are shown in fig. 3.

The algorithm for a complete Bouguer reduction is based on evaluating the gravity field generated from an ensemble of rectangular prisms as given by

$$
g=\gamma \rho \int_{z_{1}}^{z_{2}} \int_{y_{1}}^{y_{2}} \int_{x_{1}}^{x_{2}} \frac{z}{\left[x^{2}+y^{2}+z^{2}\right]^{3 / 2}} d x d y d z .
$$

The derivation of the integral equation (Plouff, 1976) is given by

$$
\begin{gathered}
g=\gamma \rho \sum_{i=1}^{2} \sum_{j=1}^{2} \sum_{k=1}^{2} \mu_{i j k}\left[z_{k} \arctan \frac{x_{i} y_{i}}{z_{k} R_{i k}}-\right. \\
\left.-x_{i} \log \left(R_{i j k}+y_{i}\right)-y_{i} \log \left(R_{i j k}+x_{i}\right)\right] \\
R_{i j k}=\sqrt{x_{i}^{2}+y_{j}^{2}+z_{k}^{2}} \\
\mu_{i j k}=(-1)^{i}(-1)^{j}(-1)^{k}
\end{gathered}
$$

where $\gamma$ is Newton's gravitational constant, $x, y$ and $z$ represent the three dimensions of the rectangular prism and $\rho$ is the uniform density.

By applying the last formula with an interactive procedure and using a number of iterations equal to the number of rectangular prisms, we obtained the gravity contribution of a distinct prismatic set. In this study, the framework of the prismatic ensemble changes depending on the topography/bathymetry features, and thus, for marine areas, the $z$-dimension of each prism is delimited by sea level (top) and sea bottom.

The optimal value of the Bouguer reduction density is crucial for this kind of reduction, since the recovered anomaly field obtained by this method represents the distribution of anomalous bodies with a density higher or lower than the fixed Bouguer density. The choice of a distinct value for density may generate suspicious anomalies. A detailed study of the optimal Bouguer reduction density for the gravity dataset of Panarea was performed by considering the relationship between the Bouguer anomaly and the bathymetry/topography data. The concept of minimizing the correlation between topography and the Bouguer anomaly derives from the pioneering work of Nettleton (1939). Since the topography effect can be observed as a scaling contamination of the gravity field mainly in the short wavelength band, it can be reduced using a cross-plot analysis of Bouguer anomaly versus topography at different densities. In the hypothesis of a perfectly rigid crust support, this correlation would appear stochastic with a null slope. On the other hand, the contribution of isostasy to the gravity data is highlighted by a negative correlation with topography (Caratori Tontini et al., 2007). To this aim, a set of cross-plots between the bathymetry/topography data and the Bouguer anomaly calculated at varying densities is shown in fig. 4 for densities ranging from 2.2 to $3 \mathrm{~g} / \mathrm{cm}^{3}$. In all cross-plots, the data can be subdivided into two distinct groups: a first group of data (black points) with negative correlation between Bouguer anomaly and bathymetry, and a second group (red points) characterized by a varying correlations (positive or negative) linked to the density used in the procedure. The negatively correlated sub-data can be associated with an isostatic mechanism, and therefore are not very sensitive to the density variation.

This leads us to conclude that if the correlation with topography has to be reduced, only the subset of the red points has relevant. The minimization procedure must take into account the different contributions from the two groups of data. In fact, a global minimization procedure of the topography effect would underestimate the optimal Bouguer density with a flattening of the large wavelength gravity anomaly. This problem may be solved by introducing a simultaneous least-squares fit of the data using two linear trends, assuming a linear relationship for the correlation between the Bouguer anomaly and bathymetry/topography (Caratori Tontini et al., 2007). The least squares fitting procedure allows us to separately process the cloud of data affected by topography contamination without introducing effects due to the negatively correlated group of data. 

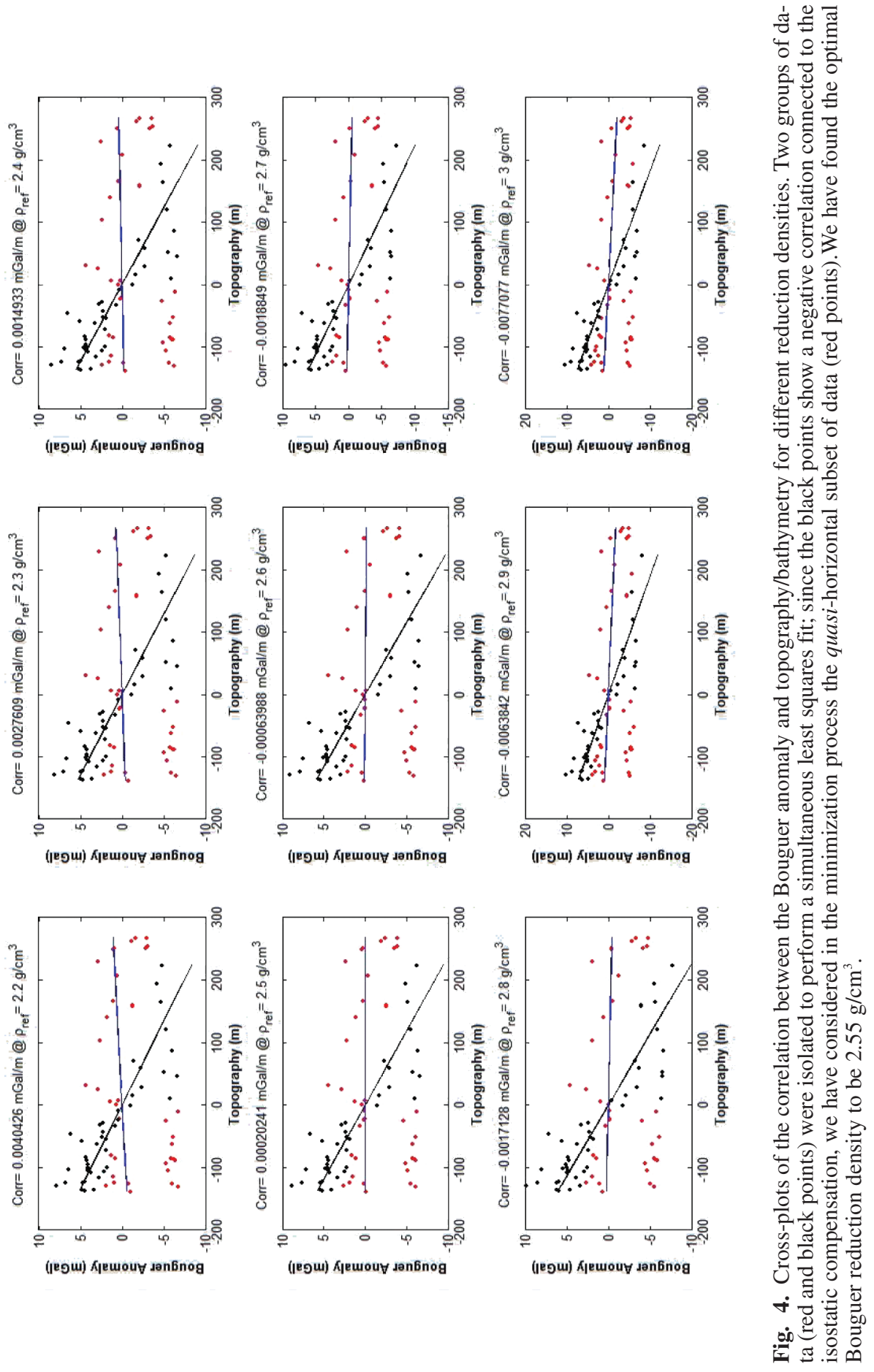


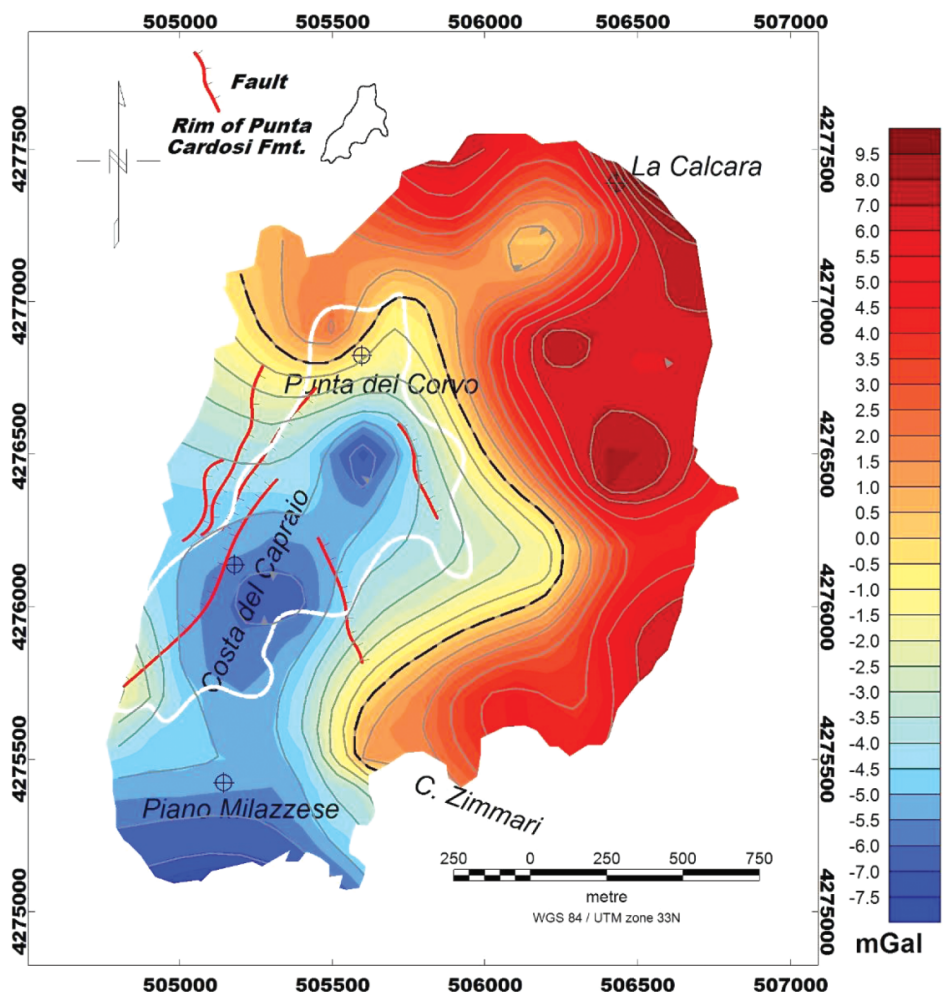

Fig. 5. Bouguer anomaly map of Panarea Island with the main structural lineaments and the rim of the youngest volcanic deposits superimposed (Punta Cardosi formation, after Lucchi et al., 2003). The black dashed line represents the zero level of the Bouguer anomaly.

Using this approach, the two groups of gravity data of Panarea Island were separated and the null slope of correlation was obtained for a Bouguer density of $2.55 \mathrm{~g} / \mathrm{cm}^{3}$. The Bouguer anomaly was then re-computed using this optimal density (fig. 5). The Bouguer anomaly field ranges from -7 to $10 \mathrm{mGal}$, with a NE-SW trending negative anomaly located at the top of the island between Costa del Capraio and Punta del Corvo; the distribution of this negative pattern is confined around the higher part of the island partly involving its southernmost sector ( $\mathrm{Pi}$ ano Milazzese). The geometric distribution of the negative anomalies partly matches the younger volcanic products of the island (Punta
Cardosi and Punta del Tribunale formations). In addition, the NE-SW trend of the negative anomaly may be correlated to the main fault system of the volcano (Calanchi et al., 2002; Lucchi et al., 2003; De Astis et al., 2003). The fault lineament eastward confines the negative anomaly, suggesting a clear relationship between local density variations and shallow deformation.

\section{Magnetic data of Panarea Island and its archipelago: acquisition and processing}

Magnetic features of Panarea Island and its archipelago were revealed by performing a de- 
tailed magnetic survey during the gravity measurement campaign. The geomagnetic prospecting was planned in two detailed surveys covering Panarea and its eastward marine sector with the islets of Basiluzzo, Lisca Bianca, Lisca Nera, Panarelli and Bottaro.

On-land magnetic prospecting of Panarea was aimed to highlight the direct relationship between the magnetic and gravity properties of the island and to provide a new integrated model for this area. The magnetic survey was planned to cover the same area of the gravity campaign, as illustrated in the survey layout of fig. 6 . The area was sampled with a non-regular grid characterized by several preferential acquisition directions, fitting the most accessible path to the top of the island. With respect to the gravity survey, the magnetic prospecting was extended to the most inaccessible areas, such as the southern sector of the island, thanks to the portability of the magnetic instruments. The magnetic anomaly field was sampled using a Geometrics pumped Cesium magnetometer. Along the acquisition tracks, the magnetic field was recorded using a sampling step of $1 \mathrm{~Hz}$, collecting about 120000 records over 4 days of acquisition.

The magnetic survey over the marine parts of the islets of Panarea was performed in cooperation with the Istituto Idrografico della Marina Militare Italiana (IIM), which provided the marine instruments and the vessel used during the surveys. A Geometrics G880 magnetometer with a single sensor based on the Cesium vapour system was used. The instrumentation was fixed on board a hydro-vessel equipped with a GPS receiver linked to the magnetometer for timing and positioning. The marine survey was designed to cover an area of $4 \times 4 \mathrm{~km}^{2}$ using 26 parallel lines spaced approximately $100 \mathrm{~m}$ apart and 6 control tie lines approximately $300 \mathrm{~m}$ apart.

The total intensity of the magnetic anomaly field for the two survey areas was reduced using daily magnetograms recorded by a fixed base station on Panarea. The fixed magnetic observatory was placed in a low noise area with a low magnetic signature. The base station worked continuously during the on-land and off-shore surveys, providing a complete time evolution of the
Earth's magnetic field. These data were useful for removing the time dependence of the magnetic signal during the prospecting. The total intensity of the magnetic signal acquired during the survey is affected by a spatial dependence on the magnetized pattern of the crust and by a time dependence directly correlated to fluctuations of the Earth's magnetic field. The spatial dependence can be obtained by subtracting the time dependent component from the total field. Thus, the collected raw magnetic data were subdivided in a daily database in which each day of acquisition was separated from the others, providing a quick time-reduction. The anomaly field of Panarea was obtained by subtracting the reference field IGRF2005 (IAGA, 2005) referenced at the geomagnetic time of acquisition from the time-reduced magnetic field. Since the two magnetic surveys were performed using different instruments and sampling steps, the on land magnetic data were processed separately from those collected at sea. In this case, the anomaly field shows errors at the intersections of the parallel and tie lines due to cross-over, which could be neglected for on-land survey. The cross-over errors were reduced using a levelling procedure, consisting of a statistical correction of misfit values computed at cross-points between tie and parallel lines. These errors can be significant when the number of lines is high, generating false anomalies connected to the high frequency component. The magnetic anomaly of the Panarea archipelago so corrected was integrated with the on-land magnetic anomaly using a grid-knits process. The global magnetic anomaly dataset was re-gridded using a common grid sampling factor of $250 \mathrm{~m}$, obtaining the map shown in fig. 7.

With regard to the magnetic properties of Panarea, it is evident that there is a topographic component that affects the magnetic anomaly, generating a positive trend in agreement with the morphologic gradient. This effect may be produced by the stacking sources of the magnetic anomaly, which increase with height. Performing a reduction to the pole (local inclination $54^{\circ}$ downward and declination $2^{\circ} \mathrm{E}$ ), is well visible that the maximum positive magnetic anomaly is located at Punta del Corvo, which represents the highest point of the island (fig. 8 ). The positive portion of the anomaly has a 


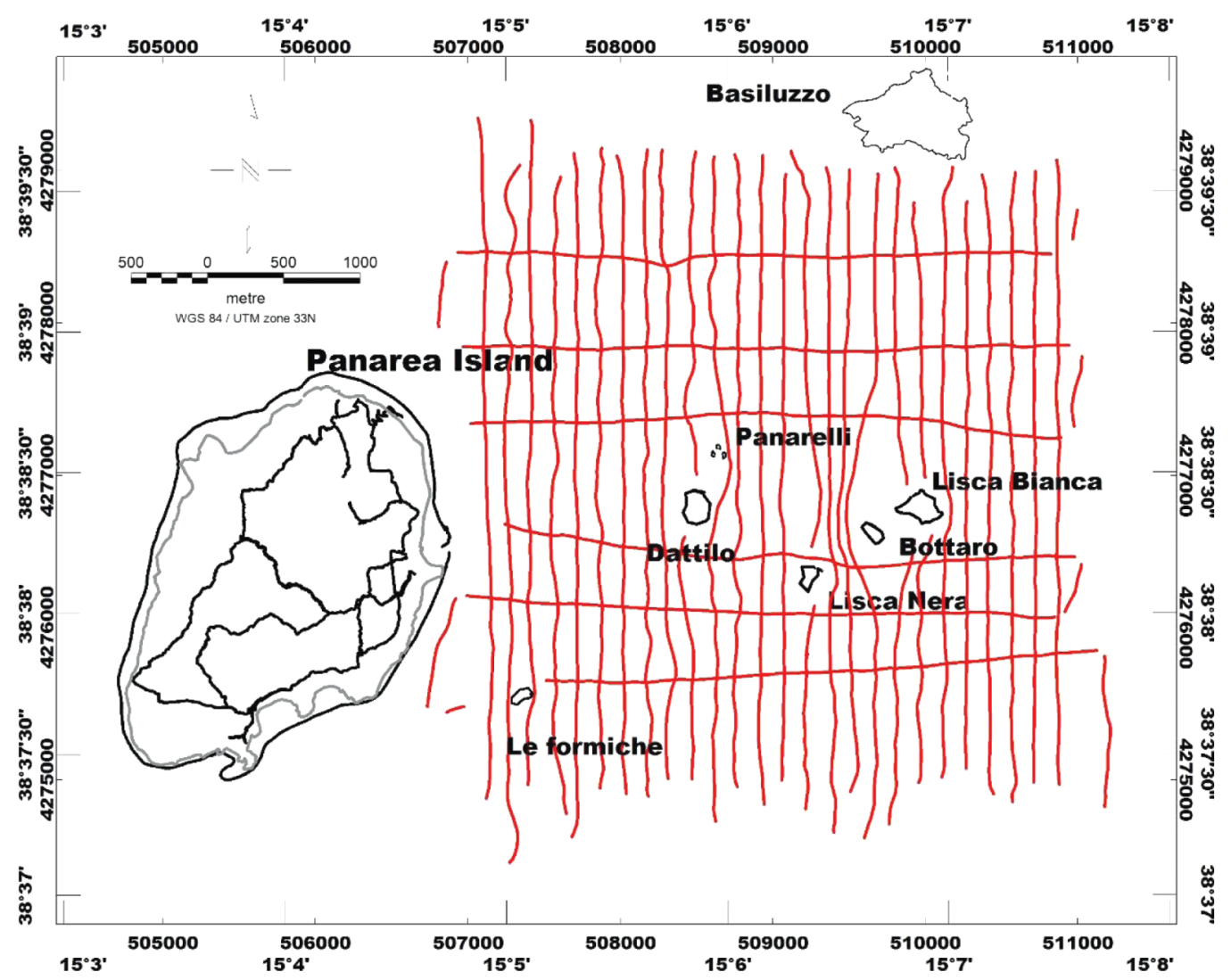

Fig. 6. Magnetic survey layout for on-land and offshore areas. The archipelago of Panarea (red lines) was surveyed by a hydro-vessel of the Istituto Idrografico della Marina, with a set of 26 parallel lines (spaced every 300 $\mathrm{m}$ ) and 6 control tie lines (spaced every $600 \mathrm{~m}$ ). The magnetic data of the Panarea cone (black lines) were sampled along accessible paths.

shape that matches the local distribution of younger volcanic deposits that tapped the volcanic edifice. These units are represented by the Punta Cardosi and Punta Falcone formations, which consist of lava domes and flows with HK-CA andesitic and dacitic compositions, combined with portions of lapilli tuff and pyroclastic breccia. The chemistry of these products does not seem very different from the other lithologies, so the strong magnetic signature may be related to the freshness of the rock samples. On the island, there are fumaroles in the southern part and in the Calcara zone which witness ongoing volcanic activity, where the amplitude of the magnetic anomaly decreases with high negative values. Thus, the diffuse phase of shallow alteration produced by the volcanic centres may have involved the volcanic deposits with a change in magnetic properties, while the younger deposits have been only slightly affected by this phenomenon.

The archipelago of Panarea shows a magnetic anomaly field strongly connected to its geologic setting, in which the gas-exhalative centre among the islets represents now the zone of actual volcanic activity. The magnetic anomaly field is mainly concentrated north of the islet of Dattilo, and is characterized by high values (500- 
$700 \mathrm{nT}$ ) with a sub-circular shape. This positive signal is isolated from the other magnetic domains of the off-shore areas, such as at Basiluzzo and the islets. So far, the magnetic features suggest a clear separation between the northern and southern parts of the archipelago, reflecting a clear structural and geological separation of the marine area. The area between the islets of Dattilo, Lisca Bianca, Lisca Nera and Panarelli represents part of the top of the Panarea volcano, and it is subject to continuous emission of gas bubbles. On November 2002, an intense shallow submarine gas eruption occurred in this area, with strong increases in the temperature of marine water from an average value of $22-23^{\circ} \mathrm{C}$ to more than $50^{\circ}$ and the formation of gas vents (Capaccioni et al., 2005, 2007). The gas eruption occurred along well-defined structural lineaments with NE-SW and NW-SE trends (Anzidei et al., 2005; Esposito et al., 2006). The gas erup- tion is still active, rising up from few exhalative points and with a much lower intensity. From a magnetic point of view, this area shows a relatively negative pattern (fig. 7) with low amplitude, ranging from -100 to $0 \mathrm{nT}$, which is compatible with shallow hydrothermal behaviour connected to the exhalative phase. The eastern portions of Dattilo and Lisca Bianca are characterized by altered-fumarolized lava flows with low or null magnetic signatures. Since this effect derives from an enduring phase of submarine exhalation, the submerged rocks located near the exhalation centres can be considered completely altered with a strong decrease in magnetic properties. The sea area between Basiluzzo and the islets is characterized by a high positive value of the magnetic anomaly field, different from the general context. Considering the reduced-to-thepole anomaly field (fig. 9), this positive is centred on a structural high delimited from Basiluz-

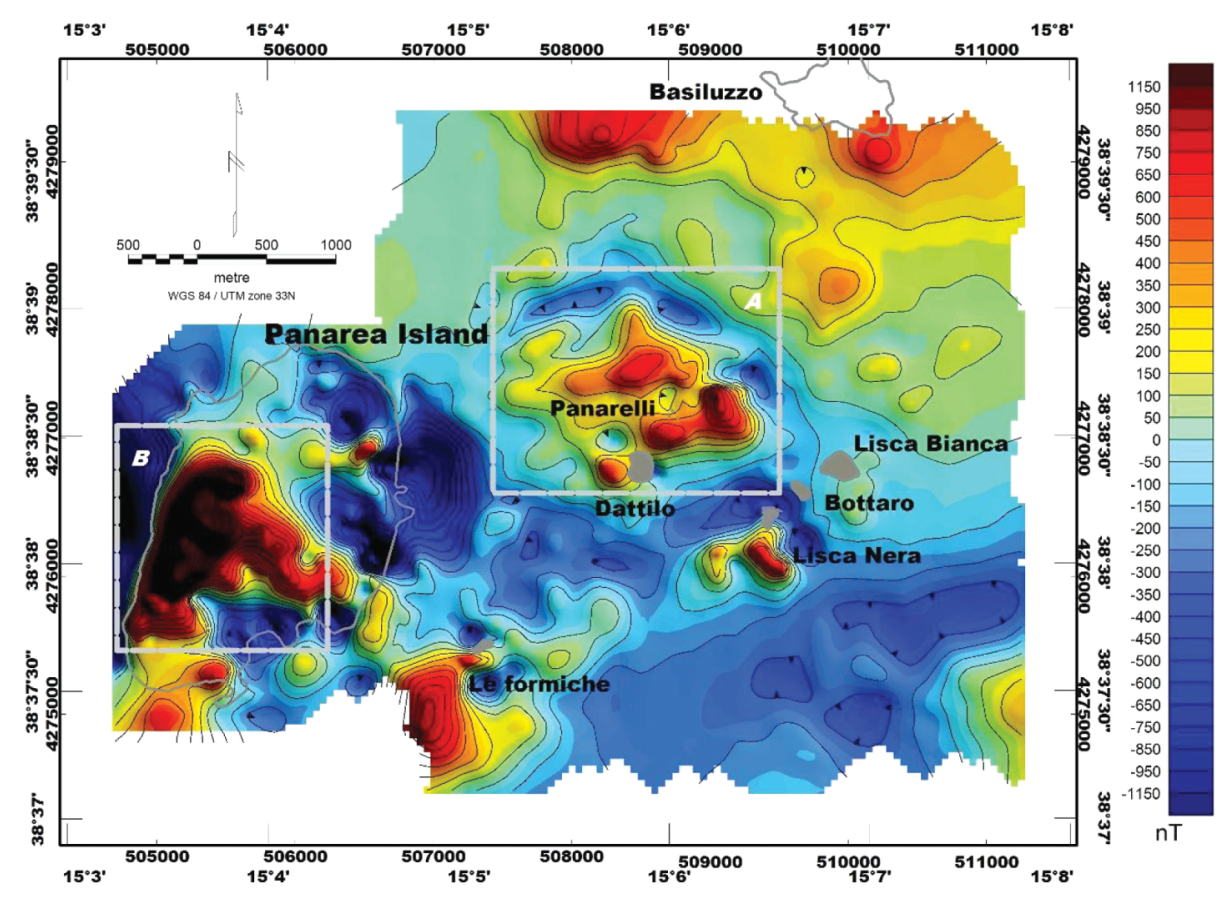

Fig. 7. Magnetic anomaly map of the integrated area of Panarea and its archipelago; contour lines are every $100 \mathrm{nT}$. The dashed grey boxes (A and B) represent the particular areas where we calculated the reduction to the pole correction. 




Fig. 8. Result of the reduction to the pole applied to the anomaly field depicted in box B of fig. 7, with the track of the main fault lineaments and the rim of Punta Cardosi formation (after Lucchi et al., 2003).

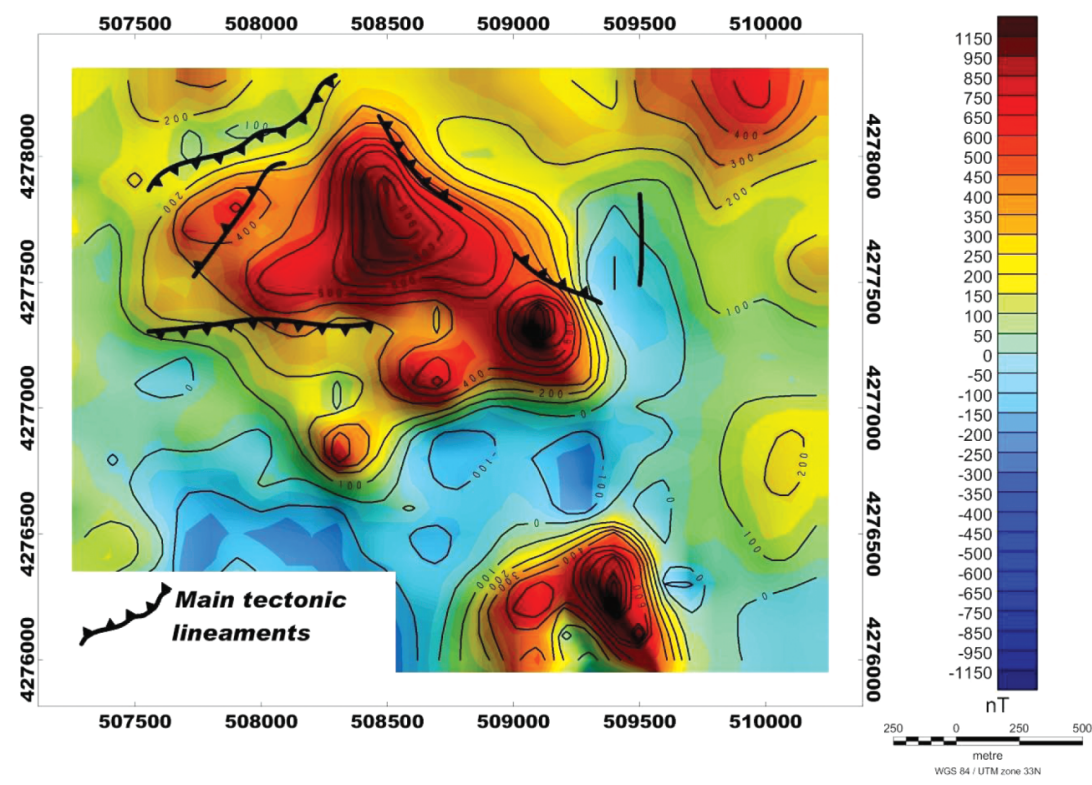

Fig. 9. Result of the reduction to the pole applied to the anomaly field depicted in box A of fig. 7. The main tectonic/morphologic features (after Anzidei et al., 2005) are superimposed on the magnetic pattern. 
zo and Dattilo Islands by several faults running E-W, NE-SW and NW-SE. These morphological and magnetic features suggest that a magma injection point could be located in this area.

\section{Conclusions}

The potential field data acquired during spring 2006, have yielded a new understanding of Panarea Island. The Bouguer anomaly map of the island was obtained after complete coverage of this volcanic area using a couple of microgravimeters and collecting more than 90 gravity station points. The raw gravity data were processed, taking into account instrumental drift, earth tides and the offset between the two gravimeters. The complete Bouguer reduction was based on estimating the real topographic contribution of the volcanic edifice by subdividing it into prismatic cells. The Bouguer reduction was constrained by correlation between the Bouguer anomaly and the morphological data. This procedure provided an optimal Bouguer density of $2.55 \mathrm{~g} / \mathrm{cm}^{3}$. The Bouguer anomaly map highlights lateral variations in density, showing a negative anomaly centred on the upper portion of the volcano, which can be interpreted as a zone of displacement where several faults are oriented NNE-SSW. This geological setting is also highlighted by the magnetic anomaly data acquired together with the gravity survey. The magnetic pattern of Panarea volcanic cone shows a topographic effect with the highest amplitude anomaly (>1100 nT) located at the top of the volcano. The large positive anomaly mainly trends NNE-SSW and NWSW, like the distribution of the youngest volcanic deposits and the fault system. Both geophysical datasets lead us to affirm that the top of the volcanic cone is mainly characterized by a sequence of young lava flows locally interrupted and displaced by a NNE-SSW and NW-SE fault system. The main distribution of the fault system is connected to regional tectonic evolution, which is characterized by movement in the NE-SW direction (Gamberi et al., 1997; De Astis et al., 2003). The zones of displacement may be interpreted as preferential tracks where the volcanic material rose up.
The magnetic anomaly connected to the volcanic structure slightly decreases as a function of height, showing local vanishing anomalies (on the northern side of the island) due to the contribution of geological units occupied by fumaroles (Calcara zone). In these areas, the effect of alteration is very high, producing a decrease in the magnetization contribution and a correlated decrease in the magnetic anomaly. The magnetic pattern of the offshore area is strictly connected to its structural setting. This area can be divided into three magnetic domains: i) Basiluzzo Island, characterized by a high positive magnetic anomaly; ii) the islets archipelago, where the magnetic anomaly field shows low negative values mainly connected to gas exhalative activity; iii) the northward sector of Dattilo, which represents a morphological structural high associated with a positive magnetic anomaly. These three structures may be interpreted as distinct magmatic/volcanic centres connected to different chronological phases of volcanic activity.

\section{Acknowledgments}

The authors are grateful to Eni Exploration and Production division for the use of two microgravimeters (Lacoste \& Romberg, Aliod model).

\section{REFERENCES}

AnZidei, M., A. Esposito, G. Bortoluzzi and F. De GiosA (2005): The high resolution bathymetric map of the exhalative area of Panarea Aeolian islands, Italy, Ann. Geophysics, 48 (6), 899-921

Barberi, F., A. Gandino, A. Gioncada, P. La Torre, A. SBrana and C. ZENuCChInI (1994): The deep structure of the Eolian arc (Filicudi-Panarea-Vulcano sector) in light of gravity, magnetic and volcanological data, $J$. Volcanol. Geotherm. Res., 61, 189-206.

BARBERI, F., P. GASPARINI, F. INNOCENTI and L. VILLARI (1973): Volcanism of the southern Tyrrenian sea and its geodynamic implications, J. Geophys. Res., 78, 5221-5232.

Beccaluva, L., G. Gabbianelli, F. Lucchini, L. Rossi and C. SAVELli (1985): Petrology and K/ Ar ages of volcanics dredged from the Eolian seamounts: implications for geodynamic evolution of the Southern Tyrrhenian basin, Earth Planet. Sci. Lett., 74, 187-208.

Billi, A., G. Barberi, C. Faccenna and G. Neri (2006): Tectonics and seismicity of the Tindari fault System, southern Italy: crustal deformation at the transition between ongoing contractional and extensional domains 
located above the edge of the subducting slab, Tectonics, 25, doi: 10.1029/2004TC001763.

BonACCORSO, A. (2002): Ground deformation of the southern sector of the Aeolian Islands volcanic arc from geodetic data, Tectonophysics, 351, 181-192.

Calanchi, N., C.A. Tranne, F. Lucchi, P.L. Rossi and I.M. VILLA (1999): Explanatory notes to the geological map 1:10.000 of Panarea and Basiluzzo islands Aeolian arc, Italy, Acta Vulcanologica, 11 (2), 223-243.

Calanchi, N., A. Peccerillo, C.A. Tranne, F. Lucchini, P.L. Rossi, P. Kempton, M. Barbieri and T.W. Wu (2002): Petrology and geochemistry of volcanic rocks from the island of Panarea: implications for mantle evolution beneath the Aeolian island arc (Southern Tyrrhenian sea), J. Volcanol. Geotherm. Res., 115, 367-395.

Caliro, S., A. Caracausi, G. Chiodini, M. DitTa, F. ItalIANO, M. Longo, C. Minopoli, P.M. NucCio, A. PAONITA and A. Rizzo ( 2004): Evidence of a new magmatic input to the quiescent volcanic edifice of Panarea, Aeolian Islands, Italy, Geophys. Res. Lett., 31, L07619, doi: 10.1029/2003GL019359.

Capaccioni, B., F. Tassi, O. Vaselli, D. Tedesco and P.L. Rossi (2005): The November 2002 degassing event at Panarea Island Italy: five months of geochemical monitoring, Ann. Geophysics, 48 (4-5), 755-765.

Capaccioni, B., F. Tassi, O. Vaselli, D. Tadesco and R. Poreda (2007): Submarine gas burst at Panarea Island (Southern Italy) on 3 November 2002: a magmatic versus hydrothermal episode, J. Geophys. Res., 112, B05201, doi: 10.1029/2006JB004359.

Caracausi, A., M. Ditta, F. Italiano, M. Longo, P.M. Nuccio, A. PAonita and A. Rizzo (2005): Changes in fluid geochemistry and physico-chemical conditions of geothermal system caused by magmatic input: the recent abrupt outgassing off the island of Panarea Aeolian Island, Italy, Geochimica and Cosmochimica Acta, 69, 3045-3059.

Caratori Tontini, F., F. Graziano, L. Cocchi, C. CarmisCIANO and P. STEFANELli (2007): Determining the optimal Bouguer density for a gravity data-set: implications for the isostatic setting of the Mediterranean Sea, Geophys. J. Int., 169, 380-388.

Chiarabba, C., L. Jovane and R. Di Stefano (2005): A new view of Italian seismicity using 20 years of instrumental recordings, Tectonophysics, 395, 251-268.

D'Agostino, N. and G. SelvagGi (2004): Crustal motion along the Eurasia-Nubia plate-boundary in the Calabrian Arc and Sicily and active extension in the Messina Straits from GPS measurements, J. Geophys. Res., 109, B11402, doi: 10.1029/2004JB002998.

De Astis, G., G. Ventura and G. Vilardo (2003): Geodynamic significance of the Aeolian volcanism (Southern Tyrrhenian Sea, Italy) in light of structural, seismological and geochemical data, Tectonics, 22 (4), 1040, doi: 10.1029/2003TC001506.

Esposito, A., G. Giordano and M. AnZidei (2006): The 2002-2003 submarine gas eruption at Panarea volcano (Aeolian Islands, Italy) Volcanology of the seafloor and implications for the hazard scenario, Mar. Geol., 227, 119-134.
FaValli, M., D. Kartson, R. Mazzuoli, M.T. Pareschi and G. Ventura (2005): Volcanic geomorphology and tectonics of the Aeolian archipelago (Southern Italy) based on integrated DEM data, Bull Volcanol., 68, 157-170.

Gabbianelli, G., C. Romagnoli, P.L. Rossi and N. CALANCHI (1993): Marine geology of Panarea-Stromboli area, Aeolian Archipelago, southeastern Tyrrhenian Sea, Acta Vulcanol., 3, 11-20.

Gabbianelli, G., P.Y. Gillot, G. Lanzafame, C. RomagnoLI and P.L. RosSI (1990): Tectonic and volcanic evolution of Panarea Aeolian Island, Italy, Mar. Geol., 92, 312-326.

Gamberi, F., P.M. Marani and C. Savelli (1997): Tectonic, volcanic and hydrothermal features of submarine portion of Aeolian arc (Tyrrhenian Sea), Mar. Geol., 140, 167-181.

GILlOT, P.Y. and J. KeLLER (2003): Radiochronological dating of Stromboli, Acta Vulcanologica, 3, 69-78.

Hollenstein, C.H., H. G. Kahle, A. Geiger, S. Jenny, S. GoEs and D. GiARDINI (2003): New GPS constraints on the Africa-Eurasia plate boundary zone in southern Italy, Geophys. Res. Lett., 30, doi: 10.1029/2003GL017554.

IAGA (INTERNATIONAL ASSOCIATION OF GEOMAGNETISM AND AERONOMY) (2005): Geomagnetic Field Modeling, the 10-th generation of International Geomagnetic Reference Field, Geophys. J. Int., 161, 561-565.

Lucchi, F., C.A. Tranne, N. Calanchi and P.L. Rossi (2007): Late Quaternary deformation history of the volcanic edifice of Panarea, Aeolian Arc, Italy, Bull. Volcanol., 69, 239-257.

Lucchi, F., C.A. Tranne, N. Calanchi, J. Keller and P.L. Rossi (2003): Geological Map of Panarea and Minor Islets Aeolian Islands (University of Bologna, University of Freiburg and INGV, L.A.C. Firenze).

MazzUOLI, R., L. TORTORICI and G. Ventura (1995): Oblique rifting in Salina, Lipari and Vulcano islands (Aeolian islands, Southern Italy), Terra Nova, 7, 444-472.

Nettleton, L.L. (1939): Determination of the density for reduction of gravimeter observations, Geophysics, 4, 176-183.

PloufF, D. (1976): Gravity and magnetic field of polygonal prisms and application to magnetic terrain corrections, Geophysics, 41, 727-741

Pondrelli, S., C. Piromallo and E. Serpelloni (2004): Convergence versus retreat in Southern Tyrrhenian Sea: Insights from kinematics, Geophys. Res. Lett., 31, L06611, doi:10.1029/2003GL019223.

Serpelloni, E., M. Anzidei, P. Baldi, G. Casula and A. GALVANI (2005): Crustal velocity and strain-rate fields in Italy and surrounding regions: new results from the analysis of permanent and non-permanent GPS networks, Geophy. J. Int., 161 (3), 861-880. doi: 10.1111/ j.1365-246X.2005.02618.x, 2005.

Tranne, C.A., F. Lucchi, N. Calanchi, G. Lanzafame and P.L. Rossi (2002a): Geological Map of the Island of Lipari (Aeolian Islands), (University of Bologna and INGV, L.A.C. Firenze).

Tranne, C.A., F. Lucchi, N. Calanchi, P.L. Rossi, T. CAMPANELLA and A. SARDELla (2002b): Geological Map of the Island of Filicudi (Aeolian Islands), (University of Bologna and INGV, L.A.C. Firenze). 